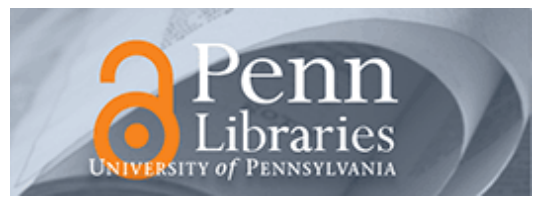

University of Pennsylvania

ScholarlyCommons

Accounting Papers

Wharton Faculty Research

$10-1972$

\title{
Income-Smoothing Behavior Under Selected Stochastic Processes
}

Nicholas J. Gonedes

University of Pennsylvania

Follow this and additional works at: https://repository.upenn.edu/accounting_papers

Part of the Accounting Commons

\section{Recommended Citation}

Gonedes, N. J. (1972). Income-Smoothing Behavior Under Selected Stochastic Processes. The Journal of Business, 45 (4), 570-584. Retrieved from https://repository.upenn.edu/accounting_papers/77

This article is available online at: http://www.jstor.org/stable/2351579

This paper is posted at ScholarlyCommons. https://repository.upenn.edu/accounting_papers/77

For more information, please contact repository@pobox.upenn.edu. 


\title{
Income-Smoothing Behavior Under Selected Stochastic Processes
}

\begin{abstract}
This paper attempts to provide a framework for clarifying and testing a version of the "income-smoothing" hypothesis. This hypothesis has been variously expressed in terms of income levels, rates of change in income, and rates of return, inter alia. In general, each version of the hypothesis is concerned with the extent to which managers may attempt to affect the volatility of a series of reported accounting numbers (or, in the case of rates of return, a series of relationships among accounting numbers) via selections and applications of accounting procedures. The alleged moti- vation for this behavior is a desire to reduce the extent to which "bad times" and-at the other extreme-"good times" are revealed by re- ported accounting numbers. It is suggested by some that a "smoothed" series of accounting numbers, particularly income numbers, will enhance the value of a firm. A typical statement of this argument was provided by Hepworth: "Certainly the owners and creditors of an enterprise will feel more confident toward a corporate management which is able to report stable earnings than if considerable fluctuation of reported earnings exists."
\end{abstract}

Disciplines

Accounting

Comments

This article is available online at: http://www.jstor.org/stable/2351579 


\section{Articles from 2013 and after}

are now only accessible on

the Chicago Journals website at

JOURNALS.UCHICAGO.EDU

Income-Smoothing Behavior under Selected Stochastic Processes

Author(s): Nicholas J. Gonedes

Source: The Journal of Business, Vol. 45, No. 4 (Oct., 1972), pp. 570-584

Published by: The University of Chicago Press

Stable URL: http://www.jstor.org/stable/2351579

Accessed: 26-05-2016 20:13 UTC

\section{REFERENCES}

Linked references are available on JSTOR for this article:

http://www.jstor.org/stable/2351579?seq=1\&cid=pdf-reference\#references_tab_contents You may need to $\log$ in to JSTOR to access the linked references.

Your use of the JSTOR archive indicates your acceptance of the Terms \& Conditions of Use, available at

http://about.jstor.org/terms

JSTOR is a not-for-profit service that helps scholars, researchers, and students discover, use, and build upon a wide range of content in a trusted digital archive. We use information technology and tools to increase productivity and facilitate new forms of scholarship. For more information about JSTOR, please contact support@jstor.org.

The University of Chicago Press is collaborating with JSTOR to digitize, preserve and extend access to The Journal of Business 


\section{Income-smoothing Behavior under Selected Stochastic Processes}

This paper attempts to provide a framework for clarifying and testing a version of the "income-smoothing" hypothesis. This hypothesis has been variously expressed in terms of income levels, rates of change in income, and rates of return, inter alia. ${ }^{1}$ In general, each version of the hypothesis is concerned with the extent to which managers may attempt to affect the volatility of a series of reported accounting numbers (or, in the case of rates of return, a series of relationships among accounting numbers) via selections and applications of accounting procedures. The alleged motivation for this behavior is a desire to reduce the extent to which "bad times" and-at the other extreme- "good times" are revealed by reported accounting numbers. It is suggested by some that a "smoothed" series of accounting numbers, particularly income numbers, will enhance the value of a firm. A typical statement of this argument was provided by Hepworth: "Certainly the owners and creditors of an enterprise will feel more confident toward a corporate management which is able to report stable earnings than if considerable fluctuation of reported earnings exists." ${ }^{2}$

* University of Chicago. I am indebted to Ray Ball, Philip Brown, Eugene Fama, Robert S. Kaplan, and, in particular, Warren Dent for their comments on earlier drafts of this paper.

1. See, e.g., M. J. Gordon, B. N. Horowitz, and P. T. Meyers, "Accounting Measurements and Normal Growth of the Firm," in Research in Accounting Measurement, ed. R. K. Jaedicke (Menasha, Wis.: American Accounting Association, 1966), pp. 221-31.

2. S. R. Hepworth, "Smoothing Periodic Income," Accounting Review 28 (January 1953): 34. A similar rationale for income-smoothing actions was advanced in M. J. Gordon, "Postulates, Principles, and Research in Accounting," Accounting Review 39 (April 1964): 32-39. Direct and indirect test of versions of the income-smoothing hypothesis are discussed in, e.g., Gordon, Horowitz, and Meyers; R. M. Copeland, "Income-Smoothing," Empirical Research in Accounting, Selected Studies, 1966, in Journal of Accounting Research 4 (suppl.): 10116; R. M. Copeland and R. L. Licastro, "A Note on Income-Smoothing," Accounting Review 43 (July 1968): 540-45; N. Dopuch and D. Drake, "The Effect of Alternative Accounting Rules for Nonsubsidiary Investments," Empirical Research in Accounting: Selected Studies, 1966, in Journal of Accounting Research 4 (suppl.): 192-219; J. Gagnon, "Purchase versus Pooling of Interests: The Search for a Predictor," Empirical Research in Accounting: Selected Studies, 1967, in Journal of Accounting Research 5 (suppl.): 187-204; T. R. Archibald, "The Return to Straight-Line Depreciation: An Analysis of a Change in Accounting Method," Empirical Research in Accounting: Selected Studies, 1967, in Journal of Accounting Research 5 (suppl.): 229-35; B. E. Cushing, "An Empirical Study of Changes in Accounting Policy," Journal of Accounting Research 7 (Autumn 1969): 196-203; P. E. Dascher and R. E. Malcolm, "A Note on Income Smoothing in the Chemical Industry," Journal of Accounting Research 8 (Autumn 1970): 
One characteristic of the available studies of the income-smoothing hypothesis is a lack of rigorously derived explicit statements about what one should expect if, in fact, income smoothing is practiced. ${ }^{3}$ Such statements are particularly important for empirical tests of the smoothing hypothesis, since it is difficult to test for the existence of something that cannot even be identified when, in fact, that something does exist. Additionally, with one exception, the available studies do not even ask whether income smoothing is optimal, given the stochastic process applicable to the accounting numbers of interest and the alleged objectives of income-smoothing actions; the one exception is a study by Ball and Watts. ${ }^{4}$ Finally, the available studies pay little (if any) attention to the multiperiod consequences of income-smoothing actions; the importance of this factor will be made clear in Section III of this paper.

Most of this paper is concerned with the optimality of incomesmoothing actions. In particular, a few beginning steps will be taken toward establishing the conditions under which income-smoothing actions are optimal (in a sense defined below). Throughout this paper, attention is restricted to the income-smoothing hypothesis expressed in terms of rates of return (e.g., rates of return on common equity, rates of return on total assets, etc.). Two classes of stochastic processes will be considered with respect to rates of return (before the effects, if any, of smoothing actions on these rates); these classes are: martingales and mean-reverting processes. Note that the techniques used herein are applicable to other versions of the smoothing hypothesis. Furthermore, if any of the stochastic processes assumed for rates of return are applicable to some other version of the income-smoothing hypothesis, then, of course, the conclusions of this paper also hold for that other version. Finally, it is important to note that this paper is only concerned with the effects (if any) of smoothing actions on reported accounting numbers. It does not deal, for example, with the effects (if any) of smoothing actions on aggregate capital market behavior. ${ }^{5}$

Before proceeding to technical developments, it may be worthwhile to briefly illustrate the importance of determining whether income-

253-59; C. E. White, "Discretionary Accounting Decisions and Income Normalization," Journal of Accounting Research 8 (Autumn 1970): 260-73; and R. Ball and R. Watts, "Some Time Series Properties of Accounting Income" (Chicago: University of Chicago, 1971) (to appear in the Journal of Finance).

3. See references in n. 2 above.

4. Ball and Watts; but, as will be indicated (see remark 5), their conclusions regarding the effects of attempted smoothing actions are not accurate, in general.

5. In this regard, it is not clear that such effects (if any) could persist, given the observed efficiency of capital markets (in particular, the New York Stock Exchange). An extensive recent review of the available theory and evidence regarding efficient capital markets is provided in E. F. Fama, "Efficient Capital Markets: A Review of Theory and Empirical Work," Journal of Finance 25 (May 1970) : 383-417. Some implications of capital market efficiency for external accounting are discussed in N. J. Gonedes, "Efficient Capital Markets and External Accounting," Accounting Review 47 (January 1972): 11-21. 
smoothing actions are optimal. This is done in Section II. Section III provides a conceptual framework for dealing with the smoothing hypothesis. Section IV provides characterizations of optimal smoothing actions. A summary is provided in Section V; the latter section also outlines some areas for additional research suggested by the results presented in this paper.

II

The existence or nonexistence of income-smoothing actions can have important implications for (1) the observed time-series properties of reported income numbers and rates of return based upon such numbers, and (2) the interpretations of these properties regarding the growth and decline of firms- two topics that have attracted considerable attention. ${ }^{6}$ For example, one might argue that, given monopolistic conditions, one should expect persistence in companies' periodic growth rates. Yet, such a time-series pattern might also be attributable to "smoothing" actions: "There are many . . . monopolistic situations that could induce persistence in earnings progress, but the same result could follow from accounting practices designed at 'managing earnings.' A clear example exists when provisions such as pension fund reserves are varied specifically to achieve a smooth earnings progression. A less blatant case arises when the profit from one effective economic transaction is taken into the income statement over several years."

On the other hand, one can also argue that some attempts to "smooth" accounting number series will have destabilizing effects; in this regard, Lintner and Glauber assert the following: "Shifts for whatever reason from one method of reporting certain types of transactions or change to another method ... may be quite destabilizing to the pattern of reported earnings, as may decisions regarding so-called extraordinary or nonrecurring credits and charges." 8

The contradictory nature of the above citations regarding the effects of attempted "smoothing" actions on the time-series properties of accounting numbers simply reflects the absence of explicit statements about the optimality of smoothing actions relative to the alleged motivation for such actions. For example, if smoothing actions have destabilizing effects on an accounting-number series and if the motivation behind attempted

6. See, e.g., I. M. D. Little, "Higgledy Piggledy Growth," Institute of Statistics, vol. 24, no. 4 (November 1962); I. M. D. Little and A. C. Rayner, Higgledy Piggledy Growth Again (Oxford: Basil Blackwell, 1966); J. Lintner and R. Glauber, "Higgledy Piggledy Growth in America" (paper presented at the Seminar on the Analysis of Security Prices, University of Chicago, May 1967); J. Lintner and R. Glauber, "Further Observations on Higgledy Piggledy Growth" (paper presented at the Seminar on the Analysis of Security Prices, University of Chicago, May 1969); R. A. Brealey, An Introduction to Risk and Return from Common Stocks (Cambridge, Mass.: M.I.T. Press, 1969); and Ball and Watts.

7. Brealey, p. 89.

8. Lintner and Glauber, p. 6. 
smoothing actions is stabilization of the number series, then why should one expect managers to pursue the application of such smoothing actions?

It has been suggested that smoothing behavior may also affect empirical results regarding the relationship between firm size and profitability. ${ }^{9}$ For example, it was suggested by Hall and Weiss ${ }^{10}$ that the effects of smoothing actions will be such that observed profitability differences across firms of different sizes will be "understated." But this specific conclusion is provided without sufficient justification. It is not obvious that (1) the underlying stochastic processes generating accounting numbers and (2) the smoothing strategies chosen by managements will combine to produce the alleged effects. Moreover, this conclusion begs the question as to whether any kind of smoothing is, in fact, optimal from management's perspective. That is the question to which we now turn.

\section{III}

In order to deal with the smoothing hypothesis, it seems necessary to distinguish between two stochastic processes: (1) the process generating basic accounting numbers and (2) that generating reported accounting numbers. Consider a firm that uses a given set of accounting procedures in order to generate its accounting numbers. Selection of these procedures may have been based upon "convenience" issues, tax regulations, industry practices, etc. Given these procedures, the resultant accounting numbers will reflect the events that affected the firm's operations. These events include: (1) events that occur within the factor-input markets in which the firm is a transactor and (2) events that occur within the firm's output markets. Such events may be specific to a particular industry, they may be economy-wide events, or they may be specific to the firm's operations. ${ }^{11}$ Let $r_{t}$ be an accounting rate of return generated at time $t$ under the given accounting procedures. Then, when looking into the future, basic rates of return may be defined as the stochastic process $\left\{\tilde{r}_{t} ; t=1\right.$,

9. This relationship was examined by, e.g., S. S. Alexander, "The Effect of Size of Manufacturing Corporation on the Distribution of Rate of Return," Review of Economics and Statistics 31 (August 1949): 229-35; H. O. Stekler, Profitability and Size of Firm (Berkeley: Institute of Business and Economic Research, University of California, 1963); and Marshall Hall and L. Weiss, "Firm Size and Profitability," Review of Economics and Statistics 49 (August 1967): 319-31.

10. Hall and Weiss, p. 321.

11. In this regard, see P. Brown and R. Ball, "Some Preliminary Findings on the Association between the Earnings of a Firm, Its Industry and the Economy," Empirical Research in Accounting: Selected Studies, 1967, in Journal of Accounting Research 6 (suppl.): 55-77; and N. J. Gonedes, "Evidence on the Information Content of Accounting Income Numbers" (report no. 7115, Center for Mathematical Studies in Business and Economics, University of Chicago, March 1971); and idem "Properties of Accounting Numbers: Models and Tests" (working paper no. 64-71-2, Graduate School of Industrial Administration, CarnegieMellon University, January 1972). 
$2, \ldots\}$ induced by the multiperiod joint-distribution function of the aforementioned events. For each $t$, this stochastic process is associated with a conditional distribution function for $\tilde{r}_{t}$, say, $F\left(\tilde{r}_{t} \mid r_{t-k} ; k=1,2\right.$, ...), $\forall t$. In the absence of smoothing actions, and given the fixed set of accounting procedures, the firm will be reporting realizations from these conditional distribution functions. That is, in this situation (and for each $t$ ), the firm's reported rate of return will be equal to the realized basic rate of return.

Now suppose that the management of the firm-in view of the basic rate of return process that it faces-decides that in each period $t$, $t=1,2, \ldots, N$, it would like to report a rate of return that is: (1) "as high as possible" and (2) "sufficiently close" to the previous period's reported rate of return. In other words, the firm's management wants to report "high" rates of return, but it does not want the reported rate-ofreturn series to be "too erratic." In order to satisfy its objective, the firm's management might have to report a rate of return (for each $t$ ) that is equal to the realized basic rate of return plus a "smoothing" (or "adjustment") factor. More generally, in this case, the reported rate-ofreturn process is a transformed basic rate-of-return process. The transformations are defined by deliberate "smoothing" actions, or accounting "manipulations." Of course, for all $t$, the rate of return reported in period $t$ will be the "previously reported" rate of return for period $t+1$. Hence, the selection of a smoothing factor for the current period must be based upon the preceding period's reported rate of return, the current period's realized basic rate of return, and the joint-distribution function of future periods' basic rates-of-return.

As before, let $\left\{\tilde{r}_{t} ; t=1,2, \ldots, N\right\}$ be the basic rate-of-return process; let $\left\{\tilde{r}_{t}{ }^{c} ; t=1,2, \ldots, N\right\}$ be the reported rate-of-return process where, for each

$$
t, \tilde{r}_{t}^{c}=\widetilde{r}_{t}+\alpha_{t} \text { and }\left\{\alpha_{t} \geq 0 ; t=1,2, \ldots, N\right\}
$$

is a sequence of smoothing factors selected by the firm's management. Until otherwise indicated, I shall assume that any selected smoothing strategy $\left\{\alpha_{t} ; 1 \leqslant t \leqslant N\right\}$ is such that

$$
\sum_{t=1}^{N} \alpha_{t}=\Omega=0 ;
$$

nonzero values of $\Omega$ will be considered in remark 6. This assumption implies that the intended effect of the smoothing strategy is simply a redistribution of rates of return (ex ante), rather than an alteration that has a "permanent" effect (relative to the finite horizon $1 \leqslant t \leqslant N$ ). For example, the distribution function for $\tilde{r}_{t^{*}}, \forall t^{*}>1$, may be based upon 
a pattern of installment-sales-revenue recognition and a particular costamortization scheme. If these sales and the expenditures underlying the costs were effected in some $\overline{\bar{t}}$ such that $\overline{\bar{t}}<t^{*}$, then (with few exceptions) the firm will know the associated cost amortizations and revenue recognitions for some $\hat{t}, \hat{t} \geqslant t^{*}$. If at the end of some $\bar{t}>1, \overline{\bar{t}}<\bar{t}<t^{*}$, the firm concludes that its realized basic rate of return for that $\bar{t}$ is "too low" relative to $r_{t-1}{ }^{c}$, then it might attempt to recognize some revenue items prematurely (relative to $t^{*}$ ), thus selecting $\alpha_{\bar{t}}>0$. But, ex ante, this action reduces the revenue recognitions for future periods. According to my formulation, all such adjustments to the basic rate of return must cumulate to zero as of $t=N$. So, it is important to note that any smoothing action in period $\bar{t}$ has implications for reported rates-of-return in some $t>\bar{t}$. In general, if a firm seeks to report a "high," but not "too erratic," rate-of-return series over the finite horizon $[1, N]$, then the selection of a smoothing action at the end of a given period must recognize the consequences of current smoothing actions vis-à-vis future periods' reported rates of return.

The preceding remarks may be formalized by expressing the smoothing problem as follows: ${ }^{12}$

$$
\begin{aligned}
& \max _{\left\{\alpha_{t} ; 1 \leqslant t \leqslant N\right\}} \mathcal{L}=E\left(\sum_{t=1}^{N} \tilde{r}_{t}{ }^{c}-\lambda\left(\tilde{r}_{t}{ }^{c}-\tilde{r}_{t-1}{ }^{c}\right)^{2}\right), \\
& \text { subject to } \tilde{r}_{t}{ }^{o}=\widetilde{r}_{t}+\alpha_{t}, \\
& \sum_{t=1}^{N} \alpha_{t}=0
\end{aligned}
$$

where $E$ is the expectation operator, and $\lambda>0$ is a parameter defining the "disutility" of squared deviations of $\tilde{r}_{t}{ }^{o}$ from $\widetilde{r}_{t-1}{ }^{o}, \forall t$. The succeeding analysis is essentially unaffected by changing the exponent of $\left(\widetilde{r}_{t}{ }^{c}-\widetilde{r}_{t-1}{ }^{c}\right)$ in (1.1) from 2 to any integer multiple of 2 . Also, as will be indicated below (see remark 6), the constraint (1.3) is less restrictive than may be inferred at first sight.

According to my formulation of the problem, the smoothing action for period $\hat{t}, \alpha_{\hat{t}}$, will be selected at the end of $\hat{t}$, after observing the realization of $\hat{r}_{\hat{t}}$. This selection is to be made so that $r_{\hat{t}}^{c}$ is "high enough" and not "too far from" $r_{\hat{t}-1}{ }^{c}$ (which is also known at time $\hat{t}$ ). In effect, $r_{\hat{t}}$, $r_{\hat{t}-k}{ }^{c}$, and $\alpha_{\hat{t}-k}, k=1,2, \ldots$, define the state of the system when $\alpha_{\hat{t}}$ is to be selected, and all $t \geqslant \hat{t}$ define the remaining stages of the $N$-stage

12. Here, I am using one formulation of the objective guiding incomesmoothing behavior, namely, minimization of a function of $\left[\widetilde{r}_{t}^{c}-\widetilde{r}_{t-1}^{c}\right]$. This objective appears to be consistent with the alleged motivation for smoothing: "stabilization" of reported number series. Some statements of the income-smoothing hypothesis would call for minimization of a function of: $\left[\tilde{r}_{t}^{c}-E\left(\tilde{r}_{t}^{c}\right)\right]$. 
problem (1.1)-(1.3). A solution to this problem, that is, a sequence of optimal smoothing actions $\left\{\alpha_{t} * ; \leqslant t \leqslant N\right\}$ should satisfy the principle of optimality: "An optimal policy has the property that, whatever the initial state and initial decision are, the remaining decisions must constitute an optimal policy with regard to the state resulting from the first decision."13

With this perspective in mind, I define the following: $f_{k}\left(S_{k}\right)=$ the $k$-stage expected return associated with the optimal action $\alpha_{k}{ }^{*}$ and the state vector $S_{k}=\left(r_{k+1} c, r_{k}, r_{k+1}, \ldots, r_{N}, \alpha_{k+1}, \alpha_{k+2}, \ldots, \alpha_{N}\right)$. Note that at stage $k$ the state vector for stage $k-1$ is a random vector because it contains the random variable $\tilde{r}_{k-1}$.

The sequence $\left\{f_{k}(\cdot)\right\}$ is defined for $k=N, N-1, \ldots, 1$ and $f_{0}(\cdot) \equiv 0$. Here, $f_{N}(\cdot)$ applies to the first stage of the problem, and $f_{1}(\cdot)$ applies to the last stage of the problem.

At the last stage of the problem $(k=1)$,

$$
\begin{aligned}
f_{1}\left(S_{1}\right) & =\max _{\alpha_{1}}\left\{r_{1}+\alpha_{1}-\lambda\left\{r_{1}^{c}-r_{2}^{c}\right\}^{2}\right\} \\
r_{1}^{c} & =r_{1}+\alpha_{1} .
\end{aligned}
$$

According to the constraint (1.2), the only feasible value of $\alpha_{1}$ is

$$
\alpha_{1}=-\sum_{k=N}^{2} \alpha_{k} .
$$

Hence, the optimal decision for $k=1$ is

$$
\alpha_{1}^{*}=-\sum_{k=N}^{2} \alpha_{k} *
$$

where $\alpha_{k} *$ for $N \geqslant k>1$ are known.

For $k=N, N-1, \ldots, 2$, one has

$$
f_{k}\left(S_{k}\right)=\max _{\alpha_{k}} E\left\{r_{k}^{c}-\lambda\left(r_{k}^{c}-r_{k+1}^{c}\right)^{2}+f_{k-1}\left(\tilde{S}_{k-1}\right)\right\},
$$

where $\tilde{S}_{k-1}=\left(r_{k}^{c}, \tilde{r}_{k-1}, r_{k}, \ldots, r_{N}, \alpha_{k}^{*}, \alpha_{k+1} *, \ldots, \alpha_{N} *\right)$. Since, at stage $k, r_{k}$ and $r_{k+1}{ }^{c}$ are known, (3) becomes

$$
f_{k}\left(S_{k}\right)=\max _{\alpha_{k}}\left\{r_{k}^{c}-\lambda\left(r_{k}^{c}-r_{k+1}^{c}\right)^{2}+E f_{k-1}\left(\widetilde{S}_{k-1}\right)\right\} .
$$

Using (2) and (4), one can define the sequence of optimal smoothing actions $\left\{\alpha_{k}^{*}, N \geqslant k \geqslant 1\right\}$ associated with the stochastic process $\left\{\tilde{r}_{k}\right\}$. And, since future rates of return are known only in terms of their distri-

13. R. E. Bellman, Dynamic Programming (Princeton, N.J.: Princeton University Press, 1957), p. 83. 
bution functions, these optimal actions will be in the form of decision rules. With the aid of some tedious algebraic manipulations, it can be shown that the solution to the problem represented by (2) and (4) is (assuming $E\left(\tilde{r}_{k}^{2}\right)<\infty, \forall k$ )

$$
\begin{aligned}
\alpha_{k}^{*}= & -\frac{\omega_{k}^{0}}{\gamma_{k}} r_{k}+\frac{\omega_{k}{ }^{\prime}}{\gamma_{k}} r_{k+1}{ }^{c}+\frac{\left(\omega_{k}^{0}-\omega_{k}{ }^{\prime}\right)}{\gamma_{k}(k-1)}\left\{\sum_{j=k-1}^{1} E\left(\tilde{r}_{j}\right)\right\} \\
& -\frac{\left(\omega_{k}^{0}-\omega_{k}{ }^{\prime}\right)}{\gamma_{k}(k-1)} \sum_{i=N}^{k+1} \alpha_{i}{ }^{*}
\end{aligned}
$$

for $k=N, N-1, \ldots, 2$; and for $k=1$,

$$
\alpha_{1} *=-\sum_{i=N}^{2} \alpha i^{*},
$$

where, for (5.1),

$$
\begin{gathered}
\omega_{k}{ }^{0}, \omega_{k}{ }^{\prime}, \gamma_{k}>0, \\
\omega_{k}^{0}>\omega_{k}{ }^{\prime}, \\
\omega_{k}{ }^{0}-\omega_{k}{ }^{\prime}>(k-1), \text { and } \omega_{k}^{0}-\omega_{k}^{\prime}>\omega_{k}{ }^{\prime} .
\end{gathered}
$$

The quantities $\omega_{k}^{0}, \omega_{k}^{\prime}$, and $\gamma_{k}$ are parameters of the decision rule for $\alpha_{l i} *$; the values of these parameters emerge from the solution of the problem represented by (2) and (4). These parameters are functions of $k$. In general, $\left(\omega_{k}^{0}-\omega_{k}{ }^{\prime}\right) /\left[\gamma_{k}(k-1)\right]$ decreases as $k$ increases; $\omega_{k}{ }^{\prime} / \gamma_{k}$ increases and $\left(-\omega^{0}{ }_{k} / \gamma_{k}\right)$ decreases as $k$ increases.

The decision rules in (5.1) and (5.2) may be used (in a straightforward manner) in order to demonstrate several interesting propositions about optimal smoothing behavior. The next section does this for some selected stochastic processes, $\left\{\tilde{r}_{t} ; N \geqslant t \geqslant 1\right\}$.

\section{IV}

This section provides characterizations of optimal smoothing actions (as defined in [5.1] and [5.2]) for selected stochastic processes. The analysis that follows considers the following question for each type of stochastic process: as of the end of stage $k=N$ (i.e., after observing the realized value of $\boldsymbol{r}_{\tilde{N}}$ ), what is the optimal value of $\alpha_{k}{ }^{*}$; in particular, is the optimal value nonzero? It turns out that the answers to this question may be had via some straightforward algebraic manipulations of the decision rule in (5.1). With a slight adjustment (see remark 1), the analysis can be extended to any stage of the process (but the conclusions for $k=N$ need not carry over to other stages of the process). Throughout, it is assumed that $r_{N}>0 ; r_{N} \leqslant 0$ is easily recognized by appropriately changing the sense of the inequalities that appear in the propositions. 


\section{Proposition A (Strict Martingale) $)^{14}$}

Suppose that the stochastic process for basic rates of return is of the form

$$
\tilde{r}_{t}=b \tilde{r}_{t-1}+\tilde{\epsilon_{t}}, \quad \text { with } \quad b=1 \text {, }
$$

where $E\left(\tilde{\epsilon}_{t}\right)=0$ and $E\left(\tilde{\epsilon}_{t}^{2}\right)<\infty$. Then

$$
\alpha_{N}^{*}=\frac{\omega_{N}^{\prime}}{\gamma_{N}}\left(r_{N+1}-r_{N}\right)
$$

and, thus, $\operatorname{sgn}\left\{\alpha_{N}^{*}\right\}=\operatorname{sgn}\left\{r_{N+1}-r_{N}\right\} .^{15}$

\section{Proof}

Under the assumptions, $E\left(\tilde{r}_{N-s}\right)=b^{s+1} r_{N+1}, s \geqslant 0$; incorporating this into (5.1) for $k=N$ yields

$$
\begin{aligned}
& \alpha_{N} *=\frac{\omega_{N}{ }^{0}}{\gamma_{N}}\left\{\frac{1}{(N-1)} \sum_{i=1}^{N-1} b^{i}-1\right\} r_{N}+\frac{\omega_{N}{ }^{\prime}}{\gamma_{N}} \\
&\left\{r_{N+1}-\frac{r_{N}}{(N-1)} \sum_{i=1}^{N-1} b^{i}\right\},
\end{aligned}
$$

and, since $b=1$, one has

$$
\alpha_{N}^{*}=\frac{\omega_{N}^{\prime}}{\gamma_{N}}\left(r_{N+1}-r_{N}\right) .
$$

Since $\omega_{N}^{\prime} / \gamma_{N}>0$, the proposition holds.

Remark 1.-The results in (7) and (8) may be easily extended to $\alpha_{k}{ }^{*}$ for $k<N$ and for the process in (6). Using (5.1) again, one has

$$
\begin{gathered}
\alpha_{k}^{*}=\frac{\omega_{k}{ }^{\prime}}{\gamma_{k}} r_{k+1}-\frac{\omega_{k}^{0}}{\gamma_{k}} r_{k}+\left(\frac{\omega_{k}^{0}-\omega_{k}^{\prime}}{\gamma_{k}(k-1)}\right)(k-1) r_{k} \\
-\frac{\omega_{k}^{0}-\omega_{k}{ }^{\prime}}{\gamma_{k}(k-1)} \sum_{i=N}^{k+1} \alpha_{i}{ }^{*} \\
\alpha_{k}{ }^{*}=\frac{\omega_{k}^{\prime}}{\gamma_{k}}\left(r_{k+1}-r_{k}\right)-\left(\frac{\omega_{k}^{0}-\omega_{k}{ }^{\prime}}{\gamma_{k}(k-1)}\right) \sum_{i=N}^{k+1} \alpha_{i}{ }^{*} .
\end{gathered}
$$

As indicated in the commentary under expression (5.5), $\left(\omega_{k}^{\prime} / \gamma_{k}\right)$ increases as $k$ increases, and $\left(\omega_{k}{ }^{0}-\omega_{k}{ }^{\prime}\right) /\left[\gamma_{k}(k-1)\right]$ decreases as $k$ increases. Hence, if $k$ is "large," the impact of $\alpha_{s}^{*}, s>k$, on $\alpha_{k}{ }^{*}$ will be "small" relative to the impact of $\left(r_{k+1}-r_{k}\right)$.

14. Martingale processes are discussed in J. L. Doob, Stochastic Processes (New York: John Wiley \& Sons, 1953); and L. Brieman, Probability (Reading, Mass.: Addison-Wesley Publishing Co., 1968).

15. The sgn (read: "signum") function is defined by $\operatorname{sgn}(x)=1$ if $x>0$, 0 if $x=0,-1$ if $x<0$. 


\section{Proposition B (Multiplicative Linear Semimartin- gale)}

Let the process for basic rates of return be as in (6) but with $b \neq 1$, and let $u_{N}=r_{N}-r_{N+1}$. Let $b \equiv(1+\epsilon)$. Then, for $N \geqslant 2$,

$$
\begin{gathered}
b>1 \text { and } u_{N}<0 \text { imply } \alpha_{N}{ }^{*}>0 ; \\
b>1 \text { and } u_{N}<\epsilon \frac{N}{2} r_{N} \text { imply } \alpha_{N}{ }^{*}>0 \\
\quad(\text { if } b>1, \epsilon>0) ; \\
b<1 \text { and } u_{N}>0 \text { imply } \alpha_{N} *<0 ; \\
0<b<1 \text { and } u_{N}>\epsilon r_{N} \text { imply } \alpha_{N}^{*}<0
\end{gathered}
$$

(Note that [a.2] implies [a.1] and, for $\epsilon>-1$, [b.2] implies [b.1]. Since the proofs for parts [a.1] and [b.1] differ from those for [a.2] and [b.2], respectively, these parts are stated separately.)

\section{Proofs}

Part a.-From (5.1) one gets

$$
\alpha_{N}^{*}=\frac{\omega_{N}^{0}}{\gamma_{N}} \Gamma+\frac{\omega_{N}^{\prime}}{\gamma_{N}} \Phi
$$

where

$$
\Gamma \equiv\left\{\frac{r_{N}}{N-1} \sum_{i=1}^{N-1} b^{i}-r_{N}\right\}
$$

and

$$
\Phi \equiv\left\{\left(r_{N}-u_{N}\right)-\frac{r_{N}}{N-1} \sum_{i=1}^{N-1} b^{i}\right\}=-\Gamma-u_{N} .
$$

If $b>1,1<b<b^{2}<\ldots<b^{N-1}$ and, thus, $\Gamma>0$. Since

$$
\alpha_{N}^{*}=\frac{\omega_{N}^{0}-\omega_{N}^{\prime}}{\gamma_{N}} \Gamma-\frac{\omega_{N}^{\prime}}{\gamma_{N}} u_{N}
$$

and $\omega_{N}{ }^{0}>\omega_{N}^{\prime}$ (see [5.1]-[5.5]), part (a.1) of proposition B holds.

In order to prove part (a.2), we note the following: If $b>1$, that is, $\epsilon>0$, then $b^{i} \equiv(1+\epsilon)^{i} \geqslant 1+i \epsilon$, with equality holding only when $i=0$ or $i=1$. Thus, for $N \geqslant 2$,

$$
\sum_{i=1}^{N-1} b^{i} \geqslant \sum_{i=1}^{N-1}(1+i \epsilon)=(N-1)+\epsilon \frac{(N-1) N}{2}
$$


Incorporating (11) into the definition of $\Gamma$ yields the result $\Gamma>$ $\epsilon(N / 2) r_{N}$ for $N \geqslant 3$ (and, of course, $\Gamma=\epsilon(N / 2) r_{N}$ for $N=2$ ). Incorporating the lower bound on $\Gamma$ into (10) yields

$$
\alpha_{N} * \geqslant \frac{\omega_{N}^{0}-\omega_{N}^{\prime}}{\gamma_{N}} \frac{\epsilon N}{2} r_{N}-\frac{\omega_{N}^{\prime}}{\gamma_{N}} u_{N}
$$

for $N \geqslant 2$. A sufficient condition for $\alpha_{N}{ }^{*}>0$ is

$$
\frac{\omega_{N}^{0}-\omega_{N}^{\prime}}{\omega_{N}^{\prime}} \epsilon \frac{N}{2} r_{N}>u_{N}
$$

Recall that $\left[\left(\omega_{N}^{0}-\omega_{N}{ }^{\prime}\right) / \omega_{N}{ }^{\prime}\right]>1$. Thus, since $\epsilon>0$,

$$
r_{N} \frac{\omega_{N}{ }^{0}-\omega_{N}^{\prime}}{\omega_{N}^{\prime}} \epsilon \frac{N}{2}>r_{N} \epsilon \frac{N}{2} \text {. }
$$

Consequently, a sufficient condition for (13) to hold (and thus a sufficient condition for $\alpha_{N}^{*}>0$ ) is

$$
u_{N}<\epsilon \frac{N}{2} r_{N}
$$

And, of course,

$$
\alpha_{N} * \geqslant 0 \quad \text { if } \quad u_{N}=\epsilon \frac{N}{2} r_{N} .
$$

Part b.-To see this part, use (9.1) and (9.2) and recognize that, if $b<1$, then $1>b>b^{2}>\ldots b^{N-1}$ and $\Gamma<0$. Using (10) again, one has $\alpha_{N}^{*}<0$ if $u_{N}>0$.

In order to prove part (b.2), note that, if $0<b<1$ (i.e., $0>\epsilon>-1)$, then, for $N \geqslant 2$,

$$
\sum_{i=1}^{N-1} b^{i} \leqslant(N-1) b=(N-1)(1+\epsilon),
$$

where the equality in (15) holds only when $N=2$. Incorporating (15) into (9.1) yields $\Gamma<\epsilon r_{N}$ for $N \geqslant 3$ and $\Gamma=\epsilon r_{N}$ for $N=2$. Using the upper bound on $\Gamma$ in (9.1) yields, for $N \geqslant 2$,

$$
\alpha_{N} * \leqslant \frac{\omega_{N}^{0}-\omega_{N}^{\prime}}{\gamma_{N}} \epsilon r_{N}-\frac{\omega_{N}^{\prime}}{\gamma_{N}} u_{N} .
$$

A sufficient condition for $\alpha_{N} *<0$ is

$$
\frac{\omega_{N}^{0}-\omega_{N}^{\prime}}{\omega_{N}^{\prime}} \epsilon r_{N}<u_{N}
$$

But, since $\epsilon<0$,

$$
\frac{\omega^{0}-\omega_{N}^{\prime}}{\omega_{N}^{\prime}} \epsilon r_{N}<\epsilon r_{N}
$$


Hence, a sufficient condition for $\alpha_{N}{ }^{*}<0$ is $u_{N}>\epsilon r_{N}$. And, of course, $\alpha_{N} * \leqslant 0$ if $u_{N}=\epsilon r_{N}$.

Remark 2.-Note from (14) that $\epsilon(N / 2) r_{N} \rightarrow \infty$ as $N \rightarrow \infty$. Thus, letting $\operatorname{Pr}(\cdot)$ denote probability, $\operatorname{Pr}\left(u_{N}<\epsilon[N / 2] r_{N}\right) \rightarrow 1$ as $N \rightarrow \infty$. Consequently, $\operatorname{Pr}\left(\alpha_{N}{ }^{*}>0\right) \rightarrow 1$ as $N \rightarrow \infty$ for $b=(1+\epsilon)$ $>1$.

Remark 3.-Expressions for $\alpha_{k}^{*}, k<N$ may be obtained by imitating the manipulations used for remark 1 . As in the latter remark, $\alpha_{k}{ }^{*}, k<N$, for $b \neq 1$, will depend upon $\alpha_{s}{ }^{*}, s>k$. And, once again, the effect of $\alpha_{s}{ }^{*}, \forall s>k$ on $\alpha_{k}{ }^{*}$ will be a decreasing function of the length of the horizon (i.e., $N$ ).

Suppose that the generating process for basic rates of return is an additive semimartingale:

$$
\widetilde{r}_{t}=\widetilde{r}_{t-1}+g+\tilde{\epsilon}_{t}
$$

where $g$ is a nonzero constant, $E\left(\tilde{\epsilon}_{t}\right)=0$, and $E\left(\tilde{\epsilon}_{t}^{2}\right)<\infty$. (If $g=0$, the process is a strict martingale; see proposition A.) For this generating process, we have for $j \geqslant 1$

$$
E\left(\tilde{r}_{N-j}\right)=r_{N}+j g .
$$

Proposition C (Additive Linear Semimartingale) Let the generating process for basic rates of return be as in (17), and let $u_{N}=r_{N}-r_{N+1}$. Then,

$$
\begin{array}{lll}
g>0 & \text { and } \quad u_{N}<g \frac{N}{2} \quad \text { imply } \quad \alpha_{N} *>0 ; \\
g<0 & \text { and } \quad u_{N}>g \frac{N}{2} \quad \text { imply } \quad \alpha_{N} *<0 .
\end{array}
$$

\section{Proof}

Using (5.1) for $k=N$, one has:

$$
\alpha_{N} *=\frac{-\omega_{N}^{0}}{\gamma_{N}} r_{N}+\frac{\omega_{N}^{\prime}}{\gamma_{N}} r_{N+1}+\left(\frac{\omega_{N}^{0}-\omega_{N}^{\prime}}{\gamma_{N}(N-1)}\right) \sum_{j=1}^{N-1} E\left(r_{N-j}\right) .
$$

From (18),

$$
\begin{aligned}
\sum_{j=1}^{N-1} E\left(r_{N-j}\right)=(N-1) r_{N}+ & g \sum_{j=1}^{N-1} j \\
& =(N-1) r_{N}+g \frac{(N-1) N}{2} .
\end{aligned}
$$

Incorporating (20) and $u_{N}=r_{N}-r_{N+1}$ into (19) and rearranging yields 


$$
\alpha_{N} *=\frac{\omega_{N}{ }^{0}-\omega_{N}{ }^{\prime}}{\gamma_{N}} g \frac{N}{2}-\frac{\omega_{N}{ }^{\prime}}{\gamma_{N}} u_{N} .
$$

A sufficient condition for $\alpha_{N}^{*}>0$ is

$$
\frac{\omega_{N}^{0}-\omega_{N}^{\prime}}{\omega_{N}^{\prime}} g \frac{N}{2}>u_{N} .
$$

Recall that $\omega_{N}{ }^{0}-\omega_{N}^{\prime}>\omega_{N}^{\prime}$. Thus, a sufficient condition for $\alpha_{N}{ }^{*}>0$ when $g>0$ is $u_{N}<g(N / 2)$. This proves part (c. 1$)$.

A sufficient condition for $\alpha_{N}^{*}<0$ is

$$
\frac{\omega_{N}^{0}-\omega_{N}^{\prime}}{\omega_{N}^{\prime}} g \frac{N}{2}<u_{N} .
$$

When $g<0$, a sufficient condition for (23), and hence a sufficient condition for $\alpha_{N} *<0$, is $u_{N}>g(N / 2)$. This proves part (c.2).

Remark 4.-Note that $g(N / 2) \rightarrow \infty$ as $N \rightarrow \infty$. Thus, $\operatorname{Pr}\left[u_{N}<\right.$ $g(N / 2)] \rightarrow 1$ as $N \rightarrow \infty$, and $\operatorname{Pr}\left(\alpha_{N}^{*}>0\right) \rightarrow 1$ as $N \rightarrow \infty$, if $g>0$. When $g<0, \operatorname{Pr}\left[u_{N}>g(N / 2)\right] \rightarrow 1$ as $N \rightarrow \infty$. Hence, for $g<0$, $\operatorname{Pr}\left(\alpha_{N}^{*}<0\right) \rightarrow 1$ as $N \rightarrow \infty$.

\section{Proposition $D$ (Mean-reverting Process)}

Suppose that $E\left(\tilde{r}_{k}\right)=\mu, \forall k$, and let $\tilde{u}_{k}=\tilde{r}_{k}-\mu$, where $E\left(\tilde{u}_{k}^{2}\right)<\infty$. Then

$$
\begin{gathered}
\alpha_{N}{ }^{*}=0 \quad \text { if } \quad \frac{u_{N}}{u_{N+1}}=\frac{\omega_{N}^{\prime}}{\omega_{N}^{0}}<1, \\
\alpha_{N}^{*}<0 \text { if } \quad u_{N+1}<0<u_{N},
\end{gathered}
$$

and

$$
\alpha_{N}^{*}>0 \text { if } u_{N}<0<u_{N+1} .
$$

\section{Proof}

Some straightforward algebra is needed to see this. Using (5.1), for $k=N, E\left(\tilde{r}_{k}\right)=\mu$, and $\tilde{u}_{k}+\mu=\tilde{r}_{k}$, one has

$$
\begin{gathered}
\alpha_{N}^{*}=\frac{-\omega_{N}{ }^{0}}{\gamma_{N}}\left(u_{N}+\mu\right)+\frac{\omega_{N}{ }^{\prime}}{\gamma_{N}}\left(u_{N+1}+\mu\right)+\frac{\omega_{N}{ }^{0}-\omega_{N}{ }^{\prime}}{\gamma_{N}} \mu ; \\
\alpha_{N}^{*}=\frac{-\omega_{N}{ }^{0}}{\gamma_{N}} u_{N}+\frac{\omega_{N}{ }^{\prime}}{\gamma_{N}} u_{N+1} .
\end{gathered}
$$

Clearly, the proposition holds. (Recall that $\omega_{N}{ }^{0}>\omega_{N}^{\prime}>0$.)

Remark 5.-If $u_{k}<0$ is interpreted as indicative of "bad times" and $u_{k}>0$ as indicative of "good times," then (24) suggests that, if "bad times" are followed by "good times," then the effect of the optimal smoothing action will be a dampening of the magnitude of the "good times." If "good times" are succeeded by "bad times," the effect will 
be a dampening of the magnitude of "bad times" (or an attempt to return to "good times"). This intuitive characterization seems to be consistent with the general, but loosely worded, statements of the smoothing hypothesis: firms will attempt to reduce the extent to which "bad times" and (at the other extreme) "good times" are revealed. And this behavior is consistent with a mean-reverting process (as described in proposition D) because "bad times" $\left(u_{N}<0\right)$ and "good times" $\left(u_{N}>0\right)$ are, on average, transient phenomena. But note that nonzero smoothing actions may be optimal for non-mean-reverting processes as well (see propositions $\mathrm{A}, \mathrm{B}$, and $\mathrm{C}$ ). Hence, contrary to the assertions of Ball and Watts, ${ }^{16}$ smoothing behavior is not, in general, "nonsense" with respect to non-mean-reverting processes; in particular, it is not "nonsense" for the problem formulation given in (1.1)-(1.3).

Remark 6.-Throughout this paper, I have imposed the constraint,

$$
\sum_{k=N}^{1} \alpha_{k}=0 .
$$

This constraint appears to be appropriate if one is examining a horizon before which and after which no nonzero smoothing actions exist. If this is not the case, then an appropriate constraint is:

$$
\sum_{k=N}^{1} \alpha_{k}=\Omega,
$$

where $\Omega$ is some nonzero constant. Imposing the constraint (26) rather than (25) would have resulted in the inclusion of the constant term, $\Omega$, in the total adjustment to $\alpha_{k}{ }^{*}$ for $\alpha_{s}{ }^{*}, s>k$. For example, instead of (5.2), that is,

$$
\alpha_{1}^{*}=-\sum_{i=N}^{2} \alpha_{i}^{*}
$$

I would have had

$$
\alpha_{1}^{*}=\Omega-\sum_{i=N}^{2} \alpha_{i}{ }^{*} .
$$

\section{V}

This paper considered the "income-smoothing" hypothesis (rate-of-return version) within the context of two kinds of stochastic processes: martingales and mean-reverting processes. A characterization of optimal smoothing action for an $N$-period horizon was derived via dynamic programming tools. This characterization provided access to several propositions regarding optimal smoothing actions under each kind of

16. Ball and Watts, p. 3. 
stochastic process and at various stages within the $N$-period horizon. These propositions indicate what one should expect if optimal smoothing is pursued by firms' managements. Moreover, they indicate that nonzero smoothing is not always optimal. The paper only dealt with the effects (if any) of optimal smoothing actions on reported accounting numbers. It did not consider the effects (if any) of smoothing actions on aggregate capital market behavior. ${ }^{17}$

The conclusions of this paper were derived by postulating an optimizing model for smoothing behavior. In principle, this approach may reduce the generality of the conclusions, but, in return, one gets specific theorems about the phenomena of interest. Empirically, of course, we only require that managers behave as if they were guided by the postulated model.

Some topics for future research are immediately suggested by the framework employed and the results presented in the above discussion. For example, given a characterization of optimal smoothing actions, it is possible to generate simulated reported rates-of-return series for simulated basic rates-of-return series. These results should permit identifications of the manner in which smoothing behavior (for various horizon lengths) may alter the statistical properties of basic rates-ofreturn series. That is, if the basic rate of return process is adequately characterized as, say, a strict martingale process, is it the case that smoothing actions will affect this process in a manner such that reported rates of return will appear to be adequately described by, say, a semimartingale process? Observe that these kinds of simulation results would also yield insights on the descriptive validity of the optimization model postulated in (1.1)-(1.3). The available empirical evidence suggests that reported rates of return are well described by martingale models. ${ }^{18}$ And, if model (1.1)-(1.3) has any descriptive validity, one should observe that, for some basic rate-of-return processes, the reported rate-of-return processes generated via (1.1)-(1.3) are adequately described by martingale models. In other words, if model (1.1)-(1.3) has descriptive validity, the time-series properties of simulated reported rates of return generated by this model, for some simulated basic rateof-return processes, should be consistent with the time-series properties of actual reported rates of return.

Finally, given the kinds of simulation results described above and given empirical proxies for basic rates-of-return series, it may be possible to conduct more refined empirical tests of the existence of income-smoothing behavior. This assertation is based on the seemingly reasonable assumption that it is futile to test for the existence of something which cannot even be (directly or indirectly) identified when, in fact, that something does exist.

17. But see n. 5 above.

18. See, e.g., Ball and Watts. 